\title{
Alternativas de gestión pública para el sector turístico El caso de Nuevo León, México
}

Recibido: 16/09/2016 · Aceptado: 13/03/2017

\author{
Aline Noyola de la Llave* \\ Centro de Investigaciones Económicas, Administrativas y Sociales \\ Instituto Politécnico Nacional \\ Hazael Cerón Monroy
}

Centro Anáhuac de Investigación en Turismo de la Universidad Anáhuac

Centro de Investigaciones Económicas, Administrativas y Sociales

Instituto Politécnico Nacional

Mauricio Magdaleno Galván

Clúster de Turismo de Nuevo León

\section{Resumen}

Algunos gobiernos mexicanos han adoptado al turismo como una estrategia importante para impulsar el desarrollo económico y la competitividad de las regiones que resguardan atractivos turísticos. Cualquiera que sea la visión gubernamental, el funcionamiento del sector turístico depende en gran medida del trabajo colaborativo y la organización de los agentes que participan en la promoción del turismo. El trabajo tiene por objetivo proponer una alternativa de gestión pública que permita organizar el sector turístico en México y, simultáneamente, ayude a consolidar ambientes competitivos para esa industria. Así, se presenta el estudio de caso de Nuevo León, en donde el gobierno se ha encargado de impulsar un modelo de gestión turística que ha hecho posible coordinar el trabajo de diferentes agentes que se añaden a la cadena de valor del turismo: el Clúster de Turismo de Nuevo León. Para generar la propuesta se utilizó la metodología de grupos de enfoque que permitiera recoger las inquietudes del sector público, privado y académico, además del estudio de casos. Los resultados han sido acciones con el propósito de mejorar la competitividad del destino.

Palabras clave: Agentes del turismo, clúster, colaboración, modelo de gestión turística, organización.

*Correo electrónico: alinnllave@icloud.com · hazael.ceron@anahuac.mx ·

mmagdaleno@clusterturismonl.com 


\title{
Public management alternative for the tourism sector The case of Nuevo León, Mexico
}

Recieved: 16/09/2016 · Accepted: 13/03/2017

\author{
Aline Noyola de la Llave* \\ Centro de Investigaciones Económicas, Administrativas y Sociales \\ Instituto Politécnico Nacional \\ Hazael Cerón Monroy \\ Centro Anáhuac de Investigación en Turismo de la Universidad Anáhuac \\ Centro de Investigaciones Económicas, Administrativas y Sociales \\ Instituto Politécnico Nacional \\ Mauricio Magdaleno Galván \\ Clúster de Turismo de Nuevo León
}

\begin{abstract}
Various Mexican governments have adopted tourism as an important strategy to promote economic development and competitiveness of those regions that have tourist attractions. Whatever the government vision is, the functioning of the tourism sector depends largely on the collaborative work and organization of those agents involved in tourism promotion. The objective of this work is to propose a public management alternative that allows organizing the tourism sector in México and, simultaneously, helps to consolidate competitive environments for this industry. The case study of Nuevo León is presented, where the government has been responsible for promoting a tourism management model that has made it possible to coordinate the work of different agents which are incorporated to the tourism value chain: the Tourism Cluster of Nuevo León. In order to generate the proposal, a focus group methodology was used to collect the concerns of the public, private and academic sectors; as were case studies. The results have been actions with the objective of improving the competitiveness of the destination.
\end{abstract}

KeY woRds: Tourism agents, cluster, collaboration, tourism management model, organization.

*E-mail: alinnllave@icloud.com · hazael.ceron@anahuac.mx · mmagdaleno@clusterturismonl.com 


\section{Introducción}

En un contexto global donde el turismo requiere de procesos y prácticas gubernamentales competitivos e innovadores que encaminen a la prosperidad del sector turístico y de los destinos, es condición indispensable coordinar, compartir e intercambiar esfuerzos y conocimientos entre los agentes del turismo, ${ }^{1}$ con el objetivo de diseñar, gestionar y promover la actividad. De tal forma, el desarrollo del sector turístico y su competitividad están en función del grado de cohesión y organización existente entre los actores que participan en un espacio o destino turístico.

Es interesante tener en cuenta que en países que experimentan recientes reformas descentralizadoras, como México, los gobiernos locales ejercen un rol determinante en el rumbo del sector turístico. No obstante, la debilidad de la administración pública en el nivel local como agente regulador del sector, la ausencia de perfiles profesionales en la materia y el desconocimiento de herramientas de gestión pública han limitado en muchas ocasiones la expansión del turismo en nuestro país. Quizá los mayores inconvenientes se atribuyen, por una parte, a la carencia de leyes y políticas que organicen la actividad turística en sus tres niveles y, por otra, a la falta de gestión en las unidades responsables de dirigir el turismo. Ante este panorama, han surgido diferentes alternativas que, desde una visión gubernamental, facilitan la gestión del sector turístico. Una de ellas es el empleo de modelos de colaboración pública y privada, que sirven como instrumento aglutinador del sector turístico y, simultáneamente, marcan pautas para el fortalecimiento de la competitividad de los destinos turísticos.

El turismo en el país ha presentado un crecimiento realmente significativo de 2013 a 2016, que lo ha posicionado en noveno lugar del ranking mundial en recepción de turistas internacionales, y Nuevo León no es la excepción, pues captó $1.6 \%$ de estos y $2.3 \%$ de los turistas nacionales en 2015, por lo que se vuelve prioritario consolidar la gestión turística. A pesar de la importancia del crecimiento del turismo en la entidad, se presentaban dificultades para

${ }^{1}$ Los agentes del turismo, entendidos como aquellos miembros de los sectores público y privado que intervienen en la actividad turística; de tal suerte que el gobierno, las empresas, la academia y la sociedad civil se configuran como actores estratégicos en el desarrollo de destinos turísticos. 
gestionar conflictos sucedidos en el sector turístico neoleonés: por un lado, se hacía evidente la incapacidad de la administración para diseñar esquemas que vincularan a los miembros de la cadena de valor del turismo y, por otro, la evaluación mostraba un sector turístico desorganizado y con escazas probabilidades de competir con otros destinos turísticos si se continuaba con la inacción en el sector; es decir, falta de competitividad.

Desde esta perspectiva, cobra relevancia la presente investigación cuyo objetivo consiste en proponer una alternativa de gestión pública que sea aplicable al sector turístico en México. Como referente práctico se desarrolla el caso de Nuevo León, entidad mexicana donde el gobierno adoptó el modelo de gestión pública que, adaptado a las características del sector turístico, permite la organización de los agentes turísticos y favorece su funcionamiento en el destino. Dada la complejidad de las leyes en Nuevo León, actualmente funciona ya el Clúster de Turismo de Nuevo León como parte de los 12 clústeres que operan bajo la economía del conocimiento.

En la primera parte de la investigación se examina la literatura que establece la relación entre la gestión pública y el turismo; en la segunda se expone la metodología empleada para la creación del clúster, que consistió en la revisión de leyes y datos y la captación de información de los agentes públicos, privados y académicos a través de grupos de enfoque; en la tercera se exponen los resultados del análisis y de la implementación del modelo de gestión -Clúster de Turismo de Nuevo León- y, finalmente, se ofrecen las conclusiones.

\section{Antecedentes: la gestión pública y los modelos de gestión turística}

La gestión pública es una categoría de análisis que no solo incorpora procesos de toma de decisión sobre problemas de interés público, sino también contempla el diseño de estrategias que mejoran las prácticas gubernamentales y, de manera simultánea, vislumbra la organización de los agentes que participan en determinados procesos de desarrollo, como el turismo. Así pues, discutir acerca de la gestión pública y su relación con la actividad turística representa una tarea compleja. No obstante, despliega un panorama que hace posible la comprensión holística sobre alternativas que ayudan a estructurar y fomentar el desarrollo del sector turístico. 
Al menos en nuestro país, la gestión pública es una disciplina que ha sido abordada por un grupo reducido de académicos como Cabrero, Aguilar, Sosa y Ramos, quienes han generado conocimiento en este ámbito con una adaptación a la realidad mexicana. Desde la visión de Cabrero, las dependencias gubernamentales presentan múltiples problemas y la gestión pública es un enfoque que responde a:

Cómo manejar adecuadamente sus recursos para sobrevivir, cómo interrelacionarse de manera óptima con otras dependencias y con el usuario (cliente) del servicio que se provee y cómo redefinir constantemente la misión para hacer viable en el largo plazo la acción institucional [Cabrero, 1998, p. 22].

Otros autores definen la gestión pública como:

El conjunto sistematizado de prácticas de un gobierno, que orientadas a promover los objetivos de desarrollo definidos por su comunidad, articulan el ejercicio de sus atribuciones establecidas en la legislación vigente en ese territorio, promueven la incorporación de otros actores públicos o privados a tareas específicas, organizan los recursos presupuestales, humanos y tecnológicos asignados a sus agencias [...] e impulsan la participación organizada y supervisión de la sociedad civil [Isunza y Méndez, 2011, p. 110].

Contrario a esta visión, Ramírez (2004) cuestiona los alcances de la gestión pública al sostener que, en un mundo globalizado, dirigido por élites políticas cuyos intereses obedecen al beneficio propio y no al comunal, las administraciones $\mathrm{u}$ organizaciones públicas tienden a transformarse en instrumentos de dominación y explotación que imposibilitan la solvencia de demandas sociales y ecológicas. Aunque Ramírez realiza una observación asertiva, no tomó en cuenta que se han diseñado nuevos mecanismos, como la transparencia, la rendición de cuentas y la participación ciudadana, que intentan descifrar y resarcir las fallas presentadas al interior de las organizaciones, de tal manera que actúan como contrapesos ante el conjunto de malas prácticas institucionales.

Es interesante destacar que autores como Ying, Arcodia y Ruhanen (2013) y Page (2014) afirman que el sector público asume una posición privilegiada dentro de la industria del turismo, debido a que su capacidad de utilizar la influencia y la autoridad para tomar decisiones hace posible transformar las condiciones que predominan en los destinos turísticos. 
Si bien los gobiernos prevalecen como agentes estratégicos para la gestión de los destinos turísticos, no se circunscriben como los únicos actores capaces de hacerlo. De hecho, Tarassiouk (2008) señala que, además del gobierno, los agentes que intervienen en el desarrollo económico son los organismos bilaterales, la sociedad civil y el sector privado. Cravacuore (2006) añade que es imprescindible afiliar a las instituciones educativas, porque su intervención genera conocimientos específicos sobre problemáticas concernientes a la gestión de los problemas que se sucitan al interior de un territorio. De esta forma es posible crear organismos de gestión donde participen los gobiernos, la iniciativa privada y la academia.

En virtud de lo anterior, la gestión pública se puede entender como el conjunto de estrategias y acciones que ideadas y accionadas desde los gobiernos $\mathrm{u}$ otros actores persiguen el estricto cumplimiento de la política pública. Para ello, se apoya en instrumentos y se orienta en el diseño de mecanismos que resulten eficientes para el ejercicio gubernamental; pretende la organización y colaboración entre los agentes que participan en determinados procesos de la administración pública; promueve el desarrollo en términos económicos, sociales, políticos y ambientales; fomenta la participación ciudadana e incentiva la transparencia de la información; trabaja en la eficacia y la eficiencia del manejo de recursos públicos, y promueve la gobernanza. ${ }^{2}$

En el enfoque de gestión, también es valioso retomar la política turística porque de ahí emanan los lineamientos, decisiones y acciones explícitos o implícitos que los agentes de gobierno han implementado o deberán implementar en materia de turismo en los niveles nacional, estatal y municipal y que al accionarse son reconstruidos por actores políticos y sociales. En nuestro país, el Plan Nacional de Desarrollo 2013-2018 (Gobierno de la República, 2013) establece de forma primordial el impulso a la innovación y la competitividad turística, así como el ordenamiento y la transformación del sector turístico. México requiere la creación y gestión de políticas turísticas, comprendidas como el conjunto de estrategias, lineamientos y acciones encaminados a la resolución de problemas turísticos que se presentan en determinadas regiones. En efecto, al buscar

${ }^{2}$ Se entiende por gobernanza el nuevo proceso directivo de la sociedad; la nueva relación que se establece entre gobierno y sociedad para definir los objetivos preferidos de la vida en sociedad y realizarlos (Aguilar, 2010, p. 24). 
ejecutar tales estrategias de la mejor manera posible, los gobiernos adquieren la facultad de desempeñar prácticas gubernamentales de calidad, y al mismo tiempo contribuyen con el cumplimiento de los objetivos de la política turística nacional.

Lo cierto es que, hasta el momento, la política turística mexicana se ha enfrentado en repetidas ocasiones a la falta no solo de colaboración, sino también de fortalecimiento de eslabones en donde se sume la presencia de la sociedad civil, la solidaridad de las empresas, la participación de las instituciones educativas y la intervención de los gobiernos; así como a la carencia de gobiernos locales que propicien la construcción de ideas, propuestas y acciones que encaminen a la prosperidad de los destinos turísticos. México requiere construir, consolidar e impulsar la industria turística a través de estrategias o instrumentos que alimenten un trabajo de cooperación, coordinación y corresponsabilidad entre los agentes del turismo.

Los modelos de gestión turística se han utilizado como uno de los dispositivos más eficaces y eficientes para tratar de organizar el sector turístico. De acuerdo con Steiner (2003), un modelo es el conjunto de estrategias cuyo propósito es cumplir con un objetivo determinado; representa una idea de lo que algo debería de ser en general, o una imagen formada de particularidades. Ahora bien, si ampliamos este concepto y lo trasladamos al ámbito turístico, un modelo de gestión turística, según la Federación Española de Municipios y Provincias (FEMP), constituye un instrumento de gran utilidad porque "organiza la actividad turística de los destinos por medio de la adaptación de esquemas de gestión a las circunstancias específicas de cada ciudad” (2008, p. 25).

Un modelo de gestión turística puede definirse como el instrumento que coadyuva a vincular, organizar y coordinar a los distintos agentes que intervienen en el fortalecimiento y desarrollo del sector turístico en cualquiera de las escalas del territorio. Se trata de un cúmulo de estrategias innovadoras que, al activarse, elevan la competitividad de los destinos turísticos, generando así una serie de beneficios económicos, sociales y políticos para la población receptora de la actividad.

Estos modelos pueden surgir desde el enfoque de alguno de los agentes turísticos, sin embargo, en México, las condiciones políticas y económicas demandan su creación desde el sector público. No obstante y como ya se mencionó, 
la gestión para el turismo exige "mayor incorporación de todas las partes con incidencia en el destino turístico, y para avanzar en la incorporación de estos otros actores, se empieza a hacer uso del concepto de gobernanza" (Queiroz y Rastrollo-Horrillo, 2015, p. 49). En este concepto y de manera simultánea se circunscriben los agentes turísticos, que, a decir de Miočić, Razović y Klarin (2016), cumplen con la función de conectar y coordinar los intereses de los diversos agentes dentro de un destino, con el propósito de diseñar productos de calidad y una imagen del sitio que convenza y atraiga a los turistas.

La FEMP señala que las características de los modelos de gestión turística pueden sintetizarse como:

i. Que sea el modelo más adaptado a la realidad turística y socioeconómica de los territorios; ii. Que sea un modelo aplicable o "implementable" y; iii. Que sea flexible, es decir, que deje la puerta abierta a las necesidades futuras, derivadas tanto de cambios en el entorno, como derivados de la propia evolución del modelo [2008, p. 47].

Naturalmente, un modelo de gestión turística persigue confeccionar trajes a la medida de los destinos turísticos. Por lo tanto, la femp sugiere que los entes de gestión turística integrarán una visión con los siguientes componentes:

i. Rol y relación con el resto de organismos e instituciones; ii. Definir la fórmula jurídica e institucional más adecuada; iii. Definición del óptimo sistema organizativo y de gestión y; iiii. Ampliar y optimizar las fuentes de financiamiento [2008, p. 27].

Desde la óptica de la FEMP y de algunos autores (Morgulis-Yakushev y Sölvell, 2017), el diseño de los modelos de gestión turística deberá afiliar los principios de eficacia, eficiencia, cooperación, corresponsabilidad, equidad, transparencia, tendencia hacia una mayor estabilidad y autosuficiencia financiera, orientación al mercado y transversalidad. Estos fundamentos derivan de la gobernanza turística, ${ }^{3}$ un tema que ha sido desarrollado por numerosos estudiosos del turismo y que se desprende del enfoque de gestión pública.

${ }^{3}$ La gobernanza turística es la búsqueda de nuevas formas de toma de decisiones colectivas sobre asuntos que implican la gestión de conflictos de intereses y que tratan de impulsar procesos de innovación social, el fortalecimiento de los actores más débiles del sistema y el cambio de las dinámicas turísticas que generan impactos negativos (Velasco, 2014). 


\section{La competitividad de los destinos turísticos}

El ímpetu actual del turismo en México gira en torno al desarrollo de destinos turísticos competitivos, sin embargo, una gran parte de estos carecen de competitividad e innovación. Esta situación ha frenado la atracción de mayores flujos turísticos y el logro de estancias más largas por parte de los turistas en los destinos nacionales. De este modo, la gestión pública se configura y apuntala como un instrumento valioso para impulsar la competitividad de los destinos.

Pulido y Pulido (2013) argumentan que un destino turístico como tal alberga una serie de productos turísticos y a ello integra a una red de autores cuyo deber es abastecer de bienes y servicios públicos y privados a los turistas. En este sentido, un destino turístico es considerado como el territorio conformado por atractivos turísticos, infraestructura y equipamiento que facilitan el intercambio comercial entre los prestadores de servicios turísticos y los turistas.

Por otra parte, el trabajo de Valls (2004) sugiere que un destino turístico debe contar con cinco características:

- Ha de construir un espacio geográfico uniforme, con características análogas y en el que se pueda establecer una planificación.

- Ha de ser un territorio al que se dirijan los visitantes y que suponga una experiencia turística, solamente con el hecho de desplazarse al mismo.

- Ha de ofrecer una oferta estructurada que satisfaga las expectativas de los visitantes, ofreciéndose en conjunto los recursos, atractivos y empresas de los que disponga tal destino.

- Ha de existir una marca que represente toda la oferta, identifique tal destino en los mercados y dé lugar a afectos y sentimientos.

- Ha de haber una comercialización conjunta del destino, existiendo para ello una planificación conjunta.

Para Pulido y López (2013), los intercambios comerciales que se suscitan en un mundo globalizado adquieren tintes de competitividad, en donde se impone el desarrollo de productos innovadores con el fin de captar más visitantes y obtener mayor derrama económica para los destinos turísticos. En cuanto a la innovación, no solo hablamos de novedades tecnológicas y de ciencia, sino también de procesos de gestión, organización y servicios. Desde esta 
visión, uno de los principales problemas en el turismo reside en la necesidad de crear experiencias mucho más atractivas para captar el mayor número de turistas y de este modo asegurar su regreso al destino (Madrid y Cerón, 2013). La innovación en el turismo requiere de procesos acumulativos de aprendizaje que generen nuevo conocimiento sobre productos y procesos, pero además de estrategias que ayuden a captar más visitantes. Por lo tanto, si la intención es crear destinos turísticos competitivos, se hace imprescindible la capacidad de innovación y creatividad.

En cuanto a la competitividad turística, Velasco (2010) plantea que la peculiaridad más importante para mantener un sector turístico compe-titivo reside en la capacidad que posee una organización, destino o sector para mantener su posición en los mercados, así como aquella que tiene para emitir mejoras que lo conduzcan a un dinámico desenvolvimiento en los mercados turísticos. En este eje de competitividad turística se incrusta la administración pública que, a decir de Medeiros (2008), tiene la pericia para manejar la competitividad como un todo, a diferencia de la industria y los negocios que basan sus intereses en sus respectivas áreas de operación. Abordar la competitividad desde la visión gubernamental, logra captar distintas dimensiones como la política, social, ambiental y económica.

En esta misma línea, Sánchez (2013) afirma que la competitividad turística es un concepto multidimensional que integra diversas variables, por lo que la importancia de esos componentes debería de ponderarse de acuerdo con las condiciones del turismo en las regiones. Asimismo destaca que un destino turístico puede no ser competitivo en su conjunto, pero albergar determinadas actividades, productos o servicios que, individualmente considerados, sí lo sean. Es decir, "puede hablarse de la competitividad turística de un país en su conjunto, de una región del mismo, de una comarca, de una ciudad, de un complejo turístico, de un hotel, de un producto, de un servicio turístico concreto, etc." (Sánchez, 2013, p. 207).

A partir del marco anterior, se considera que la competitividad es un elemento imprescindible en la gestión turística porque actúa como plataforma que permite al destino turístico permanecer en ventaja respecto a otros. El trabajo de Valls (2004) plantea que el verdadero éxito de la gestión de un destino turístico dependerá de la capacidad de los distintos agentes para desempeñar sus 
respectivos roles y para establecer, entre todos, el consenso en torno al modelo de desarrollo turístico y a su estricta aplicación a lo largo del tiempo. De tal modo, la competitividad de los destinos turísticos se encuentra en estricto apego al desarrollo de modelos de gestión que apoyan en la creación de estrategias para el turismo.

De manera concluyente, se subraya que el diseño de modelos de gestión turística ha cobrado más auge en países desarrollados, cuyas condiciones económicas, políticas, ecológicas y sociales distan de la realidad mexicana. No obstante, podemos introducir nuevos conceptos e ideas que paulatinamente deben permear en nuestra lógica. Remitirse al cómo se está actuando y no al cómo se debería actuar ha sido una constante que impide el progreso de muchas de nuestras actividades económicas y, en este caso, de la turística.

\section{Turisme de Barcelona: un modelo de gestión a imitar}

La teoría de la gestión pública se ha construido a partir del análisis de estudios de caso. De acuerdo con los planteamientos de Barzelay (2003), la gestión pública debe comprenderse por medio de la práctica basada en experiencias, de modo que el uso paulatino de estudios de caso en todo el mundo ayuda a asimilar de una mejor forma los procesos de gestión pública y, a su vez, conduce a la obtención de un rigor metodológico en esta disciplina. Asimismo, Yin (2012) realiza notables contribuciones al señalar que un estudio de caso será una investigación aplicada a un fenómeno dentro de su contexto y concluye con nuevos aprendizajes acerca del comportamiento del mismo.

Sobre las ideas plasmadas con anterioridad, este documento retoma un ejemplo de éxito en el nivel global referente a la gestión de destinos. En efecto, se describe de manera general el funcionamiento del Consorcio de Turisme de Barcelona, constituido en 1993 por el Ayuntamiento de Barcelona, la Cámara Oficial de Comercio, Industria y Navegación de Barcelona y la Fundación para la Promoción Internacional de Barcelona. El objetivo de esta asociación públicoprivada es promover el turismo a lo largo de Barcelona, mediante estrategias comerciales, marketing y social media.

El consorcio cuenta con dos fuentes de ingresos: las aportaciones que realizan los tres socios y los recursos propios generados por la prestación y comercialización de productos y servicios de Turisme de Barcelona. Entre los 
recursos propios sobresalen el Bus Turístic, cuya explotación inició Turisme de Barcelona; la Barcelona Card, una tarjeta combinada que permite múltiples usos, y el Mirador de Colón, que siempre había formado parte del Patronato Municipal de Turismo. Adicionalmente, numerosas empresas e instituciones aportan bienes y servicios turísticos que han sido útiles para la comercialización.

La participación pública y privada se distribuye en partes iguales, y la presidencia corresponde siempre a un empresario del sector. Se organiza a partir de un Consejo General, presidido por el ayuntamiento de la ciudad, y un Comité Ejecutivo en el que lidera una personalidad del sector turístico nombrada por la Cámara de Comercio. Tiene como objetivos centrales la consolidación de la atracción turística en Barcelona, el impulso de la oferta comercial, el incremento del gasto del visitante, la expansión de la oferta turística y la búsqueda de nuevos nichos de mercado. Actualmente, Turisme de Barcelona es un modelo exitoso de gestión turística puesto que logró que el gobierno de la ciudad le cediera el control turístico de uno de los destinos más visitados en el mundo.

\section{Metodología}

Este documento presenta la metodología empleada para la creación del organismo llamado Clúster de Turismo de Nuevo León. Se utilizó una metodología cualitativa que descansa en la revisión de la literatura y el estudio de caso del Consorcio de Turisme de Barcelona, así como en el análisis de leyes y reglamentos que regulan la actividad turística en Nuevo León. La metodología también hizo uso de la técnica de grupos focales y entrevistas a profundidad dirigidas a informantes clave de la industria turística neoleonense, lo cual hizo posible captar las inquietudes del sector turístico empresarial, académico y gubernamental para diseñar un modelo inicial de gestión turística en Nuevo León.

Al comienzo de la investigación se desarrolló el sustento teórico seguido del estudio de caso de Turisme de Barcelona. Luego se examinaron los instrumentos legales que regulan el turismo de la entidad: la Ley de la Corporación para el Desarrollo Turístico de Nuevo León (Codetur); la Ley y Reglamento de Fomento a la Inversión y al Empleo, y el Acuerdo por el que se crea el Consejo Ciudadano para el Impulso de la Industria Turística de Nuevo León.

Posteriormente, se realizó una comparativa entre los lineamientos de la Ley de la Codetur y su ejecución por parte de la administración turística durante 
los últimos cinco años. La verificación de esta ley responde a su vigencia, pues fue decretada hace más de diez años y aún se sitúa como el máximo estatuto en materia de turismo en la entidad. Tal normativa se encarga de asignar la forma de organización, objetivos y facultades de la Codetur, del director general y del Consejo Ciudadano de Turismo. Además, se exploró la Ley y el Reglamento de Fomento a la Inversión y al Empleo para establecer el tipo de política que dirigía a la industria turística. Finalmente, se estudió el decreto que ampara la creación del Consejo Ciudadano para el Impulso de la Industria Turística de Nuevo León, mismo que hizo posible reconocer al turismo como un sector económico prioritario en la escena estatal.

Aunado a lo anterior, se implementó la técnica de grupos focales que "privilegia el habla, y cuyo interés consiste en captar la forma de pensar, sentir y vivir de los individuos que conforman el grupo" (Varela y Hamui, 2013, p. 57). Se conformaron dos grupos focales y se consideró integrar cada conjunto por un representante del sector público, del sector privado y del sector académico.

En el cuadro 1 se observa a los agentes entrevistados mediante la técnica de grupos focales.

CuAdRo 1. Entrevistados mediante la técnica de grupos focales

$\begin{array}{lll}\text { Grupo focal } & \text { Sector } & \text { Institución } \\ \text { Grupo } 1 & \text { Público } & \text { Secretaría de Desarrollo Económico } \\ \text { Grupo } 1 & \text { Privado } & \text { Aeropuerto de Monterrey (omA) } \\ \text { Grupo } 1 & \text { Académico } & \text { Universidad Autónoma de Nuevo León } \\ \text { Grupo } 2 & \text { Público } & \text { Subsecretaría de Turismo } \\ \text { Grupo } 2 & \text { Privado } & \text { Operadora Luxor Hotels } \\ \text { Grupo } 2 & \text { Académico } & \text { Universidad de Monterrey (UDEM) }\end{array}$

Fuente: Elaboración propia.

La última etapa comprendió una serie de entrevistas a profundidad dirigidas a distintos organismos de gestión de destinos (DMo) de todo el mundo, en donde la organización del turismo se confecciona bajo modelos de cooperación y vinculación estrecha entre la administración pública y la iniciativa privada. Los casos de estudio de clústeres considerados se mencionan a continuación: 
- Consorcio de Turisme de Barcelona

- Clúster de Turismo de Galicia

- Clúster de Turismo de Asturias

- Clúster de Turismo de las Islas Canarias

- Clúster de Turismo de Extremadura

- Clúster de Turismo de Madrid

- Clúster Turístico del destino Puerto Plata

- Clúster Turístico de Santo Domingo

Con excepción de la entrevista dirigida al director del Consorcio de Turisme de Barcelona, que se llevó a cabo de manera presencial en septiembre de 2015, los directores y presidentes de los DMo concedieron entrevistas vía Skype que fueron grabadas y ulteriormente transcritas para su análisis. Los diálogos tuvieron lugar entre junio y diciembre de 2015.

Para examinar la información recabada se tomó en cuenta la técnica del análisis del discurso. De acuerdo con Santander (2011), las opiniones que expresan los sujetos entrevistados no solo permanecen en el plano de las ideas sino que trascienden y construyen una realidad social, dicho de otra forma, "analizar el discurso que circula en la sociedad es analizar una forma de acción social” (Santander, 2011, p. 210). El cuadro 2 contiene las categorías discursivas que fueron contempladas y estudiadas para el desarrollo del modelo de gestión turística neoleonés.

CuAdRo 2. Categorías y subcategorías empleadas para el análisis del discurso

\begin{tabular}{|c|c|c|}
\hline Categorías & Gestión pública & Turismo \\
\hline Subcategorías & $\begin{array}{l}\text { Cooperación } \\
\text { Colaboración } \\
\text { Marco normativo } \\
\text { Capacidades institucionales } \\
\text { Consenso } \\
\text { Planeación } \\
\text { Gobernanza } \\
\text { Política turística } \\
\text { Alianzas estratégicas } \\
\text { Financiamiento y grado de } \\
\text { participación }\end{array}$ & $\begin{array}{l}\text { Competitividad del destino } \\
\text { Capacidad para la innovación } \\
\text { Conservación y mejora de los } \\
\text { atractivos } \\
\text { Marketing turístico } \\
\text { Acceso y movilidad } \\
\text { Comunicación, internet e } \\
\text { infraestructura turística } \\
\text { Percepción de la comunidad acerca } \\
\text { del turismo } \\
\text { Sustentabilidad }\end{array}$ \\
\hline
\end{tabular}

Fuente: Elaboración propia. 


\section{Resultados}

El turismo de Nuevo León ha presentado un incremento en la llegada de visitantes internacionales y nacionales. Según datos de Datatur (2016), el crecimiento del turismo se dinamiza principalmente por los turistas nacionales. De 2011 a 2014 el aumento de los turistas internacionales tuvo tasas hasta de dos dígitos (véase cuadro 3).

CUADRo 3. Número de turistas nacionales y extranjeros y tasas de crecimiento en Nuevo León, 2000-2015

\begin{tabular}{ccccccc} 
Año & $\begin{array}{c}\text { Total de } \\
\text { turistas }\end{array}$ & Nacionales Extranjeros & $\begin{array}{c}\text { Tasa de } \\
\text { crecimiento } \\
\text { \%) total de } \\
\text { turistas }\end{array}$ & $\begin{array}{c}\text { Tasa de } \\
\text { crecimiento } \\
\text { (\%) total }\end{array}$ & $\begin{array}{c}\text { Tasa de } \\
\text { crecimiento } \\
\text { (\%) total }\end{array}$ \\
\hline 2000 & 1627257 & 1359466 & 267791 & - & - & - \\
2001 & 1694097 & 1411714 & 282384 & 4.1 & 3.8 & 5.4 \\
2002 & 1654831 & 1383522 & 271309 & -2.3 & -2.0 & -3.9 \\
2003 & 1685891 & 1435220 & 250671 & 1.9 & 3.7 & -7.6 \\
2004 & 1683577 & 1426231 & 257346 & -0.1 & -0.6 & 2.7 \\
2005 & 1843858 & 1528874 & 314983 & 9.5 & 7.2 & 22.4 \\
2006 & 1887644 & 1556611 & 331033 & 2.4 & 1.8 & 5.1 \\
2007 & 2189570 & 1814765 & 374805 & 16.0 & 16.6 & 13.2 \\
2008 & 2229964 & 1838642 & 391321 & 1.8 & 1.3 & 4.4 \\
2009 & 1903941 & 1639731 & 264210 & -14.6 & -10.8 & -32.5 \\
2010 & 1687135 & 1467702 & 219433 & -11.4 & -10.5 & -16.9 \\
2011 & 1621573 & 1461381 & 160192 & -3.9 & -0.4 & -27.0 \\
2012 & 1744074 & 1531188 & 212886 & 7.6 & 4.8 & 32.9 \\
2013 & 1908023 & 1572207 & 335816 & 9.4 & 2.7 & 57.7 \\
2014 & 2091330 & 1676436 & 414895 & 9.6 & 6.6 & 23.5 \\
2015 & 2312124 & 1974720 & 337404 & 10.6 & 17.8 & -18.7 \\
\hline
\end{tabular}

Fuente: Estimación propia con datos de Datatur, 2016.

Además, el porcentaje de ocupación se vio deteriorado de 2000 a 2011, pero recientemente se ha elevado de nuevo hasta llegar a $65 \%$ en 2015. 


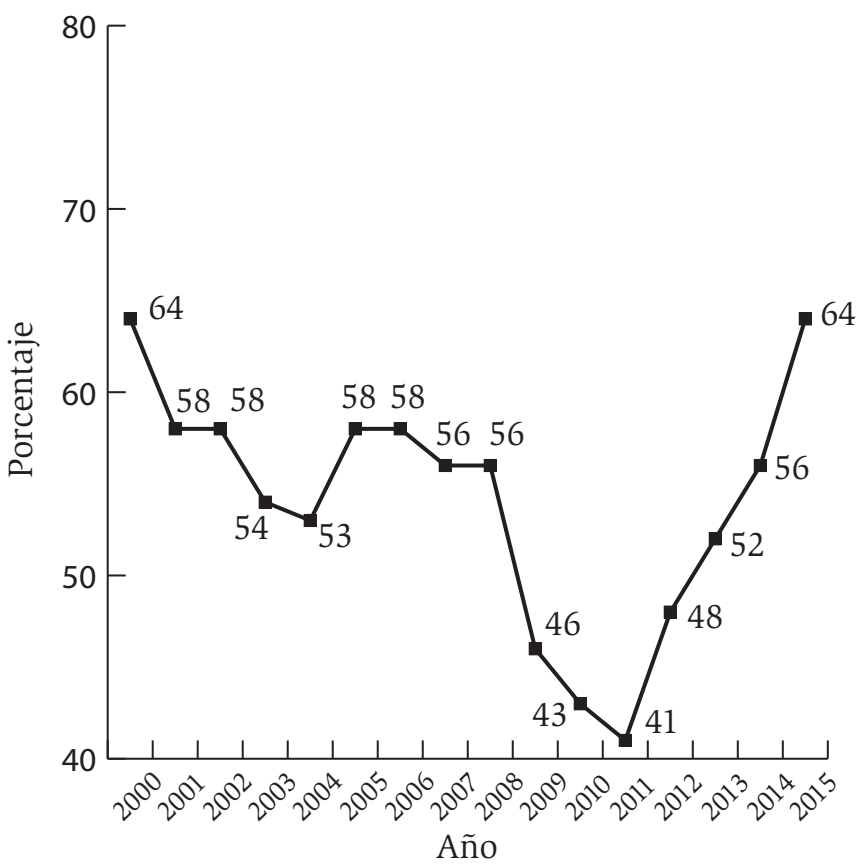

Fuente: Estimación propia con datos de Datatur, 2016.

FiguRa 1. Porcentaje de ocupación en los hoteles de Nuevo León, 2000-2015 (\%)

Ambos indicadores denotan el reto del crecimiento del turismo en Nuevo León y la necesidad de su gestión adecuada.

\section{Análisis del marco legal}

La revisión del marco legal del turismo de Nuevo León y su confrontación con las prácticas gubernamentales plantearon un panorama en el que la administración turística pausó la ejecución de ciertos lineamientos fundamentales para el desarrollo de la actividad turística. Los resultados son los siguientes:

- Se constató la inexistencia de una Ley para el Turismo en la entidad, circunstancia que continúa posicionando a Nuevo León como uno de los pocos estados de la república mexicana que no cuenta con legislación en la materia. 
- A pesar de la facultad que se le otorgaba a la administración turística para generar recursos propios o recibirlos de fondos nacionales o internacionales y comercializar productos, se observaba la falta de gestión y vinculación con otros agentes turísticos, así como de capacitación para bajar recursos de la federación u otras entidades financieras.

- Si bien la Ley menciona la necesidad de fomentar la participación ciudadana, no se diseñaron mecanismos que incluyeran la opinión de la sociedad y su involucramiento en los procesos turísticos.

- Se limitaba la creación de empresas y programas de capacitación al personal ocupado en el sector turístico, cuestión que desencadenó una oferta de servicios turísticos de baja calidad y con poca atracción para los turistas.

- El turismo padecía de estrategias orientadas a nuevos mercados y tendencias globales, es decir, se estaba omitiendo la implementación de tecnologías de información para el turismo y el desarrollo de productos innovadores y competitivos en el nivel nacional.

- A pesar de las atribuciones y la representación plural de la Codetur, esta solo funcionaba como un órgano consultivo y no incluía la participación de otros sectores que inciden en el desarrollo del turismo.

\section{Grupos de enfoque y entrevistas}

La información que se obtuvo tanto en los grupos de enfoque como en las entrevistas a profundidad evidenció la necesidad de diseñar alternativas para mejorar las condiciones del turismo en la entidad. Según las opiniones de los informantes clave, el turismo no se puede impulsar de manera aislada porque requiere la suma de trabajo, colaboración y voluntad por parte de los integrantes de la cadena de valor turística. Es conveniente puntualizar que las preguntas se diseñaron en función de las categorías y subcategorías que sugiere la revisión de la literatura del presente documento.

En palabras de Jordi W., director general del Consorcio de Turisme de Barcelona:

Ninguno de los dos sectores, ni el público ni el privado, tiene la suficiente fuerza para hacer las cosas por sí solos. Si el sector privado se quiere imponer sobre el 
sector público, fracasa. Si el sector público se quiere imponer sobre el sector privado, fracasa. Cuando se conjunta el espíritu público del privado, la voluntad de estos sectores, entonces se propicia el éxito. Las grandes transformaciones de Barcelona se han realizado gracias al acuerdo tácito y explícito que se mantiene entre nuestros socios [entrevistado por Noyola, 2015].

Sobre la misma línea de participación y colaboración, los representantes de los clústeres turísticos de otros países coinciden con la idea de que Latinoamérica presenta un problema fundamental: los ayuntamientos duran cuatro años, con lo cual no se puede garantizar estabilidad en los destinos turísticos. Si el objetivo es generar y consolidar una política turística, se necesita de muchos años y de una visión a largo, mediano y corto plazo. Es importante seguir con una ruta crítica y continuar con ella en cada administración. Enfocarse más en la alternancia que en la falta de ejecución de la política turística repercutirá en el bajo desempeño de las alianzas estratégicas.

En el discurso también hubo similitudes en cuanto a la necesidad de innovar constantemente y crear productos y rutas turísticas que coadyuven a distribuir los beneficios de la actividad en todas las regiones que integran un destino. Además, los agentes coinciden con la envergadura de incorporar las tecnologías de la información a la promoción de los destinos turísticos; elevar su competitividad, insertarse y hacerse presentes en un mundo globalizado con múltiples interconexiones entre los turistas y los prestadores de servicios.

Por otro lado, se encontraron discrepancias en las ideas de los informantes respecto a las fuentes de financiamiento. Una parte de los entrevistados argumenta que el sector gubernamental está obligado a contribuir con la mayoría de los ingresos toda vez que es una actividad que genera beneficios para los ayuntamientos. Otros insisten en que el sector privado posee mayor capacidad y habilidad para sumar aliados comerciales a la asociación que impriman dinamismo y garanticen la duración del clúster.

En lo que atañe a ambos grupos de enfoque, los miembros de las instituciones convergen con el hecho de crear convenios de colaboración ante organismos públicos y privados en los niveles nacional e internacional, que aporten valor al organismo o la industria turística, buscando constantemente la transferencia de conocimientos y de innovación. A esto se añade la disposición y visión común de unir esfuerzos para ser un organismo que fomente la transparencia 
y la rendición de cuentas a través de un mecanismo de comunicación de los proyectos, actividades y resultados del ente. El grupo uno manifiesta su interés por facilitar la movilidad de los visitantes en el destino, promover el espíritu empresarial y apoyar a las pymes para hacer crecer sus negocios y así se integren a la cadena de valor del turismo.

Contrario a esta comunidad, en las preguntas referentes al grado de participación y colaboración de los socios aún no se contaba con la claridad para diseñar acuerdos sobre la manera en la que se aceptaría o no la participación de otros aliados en la asociación público-privada llamada clúster.

\section{Creación del modelo de gestión turística}

A la luz de la información obtenida en los diálogos con los representantes de los modelos de gestión turística consultados, se visualizó una ventana de oportunidades para enriquecer la gestión del destino. Una vez que se indagaron estas alternativas, se adoptó a Turisme de Barcelona como modelo aspiracional para Nuevo León porque es un esquema exitoso en el nivel mundial y se acopla de mejor forma al funcionamiento de la industria turística estatal.

De este modo, se creó el Clúster de Turismo de Nuevo León A. C., organismo que contribuye a gestionar el turismo neoleonés y cuya función se realiza principalmente a través de la toma de decisiones estratégicas entre el gobierno, las empresas y el sector académico, asociación bajo el régimen de triple hélice.

En virtud del amparo de la Ley de Fomento a la Inversión y al Empleo del estado y bajo el acuerdo por el que se crea el Consejo Ciudadano para el Impulso de la Industria Turística de Nuevo León, el modelo nació en mayo de 2015 como asociación civil. Esta figura pretende impulsar el desarrollo económico estatal por medio de la competitividad del sector turístico; la creación de nuevos empleos de alto valor agregado; la productividad y la sustentabilidad; todo ello como consecuencia de un trabajo colaborativo que fomenta la incorporación de tecnologías aplicadas al turismo y la transferencia de conocimiento entre los miembros del clúster.

Como es posible observar en la figura 1, el ala gubernamental del Clúster de Turismo de Nuevo León está conformada por las siguientes instituciones estatales: Secretaría de Desarrollo Económico a cargo de la Secretaría Técnica; Codetur, con la función de secretario ejecutivo; e Instituto de Cultura Física y 
Deporte de Nuevo León (INDE), Secretaría de Salud, Instituto de Innovación y Transferencia Tecnológica (I2T2) y Parque Fundidora como vocales. En cuanto a la iniciativa privada, la Operadora Luxor Hotels preside el Consejo; el Buró Inmobiliario Nacional S. A. de C. V. (Hoteles Fiesta Inn) ocupa la Vicepresidencia; el Centro Internacional de Negocios A. C. (Cintermex) tiene el cargo de tesorero y los otros miembros son vocales, entre ellos: Aeropuerto de Monterrey S. A. de C. V., Grupo Senda Autotransportes S. A. de C. V., Grupo Súper Espectáculos S. A. de C. V. (Zignia Live), Servicios Profesionales de Aventura S. A. de C. V. (Ibo Adventures) y el restaurante El Gusto de Santiago S. A. de C. V. Finalmente, el sector académico incluye la participación de las principales universidades de Nuevo León, como la Universidad Autónoma de Nuevo León, la Universidad de Monterrey y la Universidad Regiomontana.

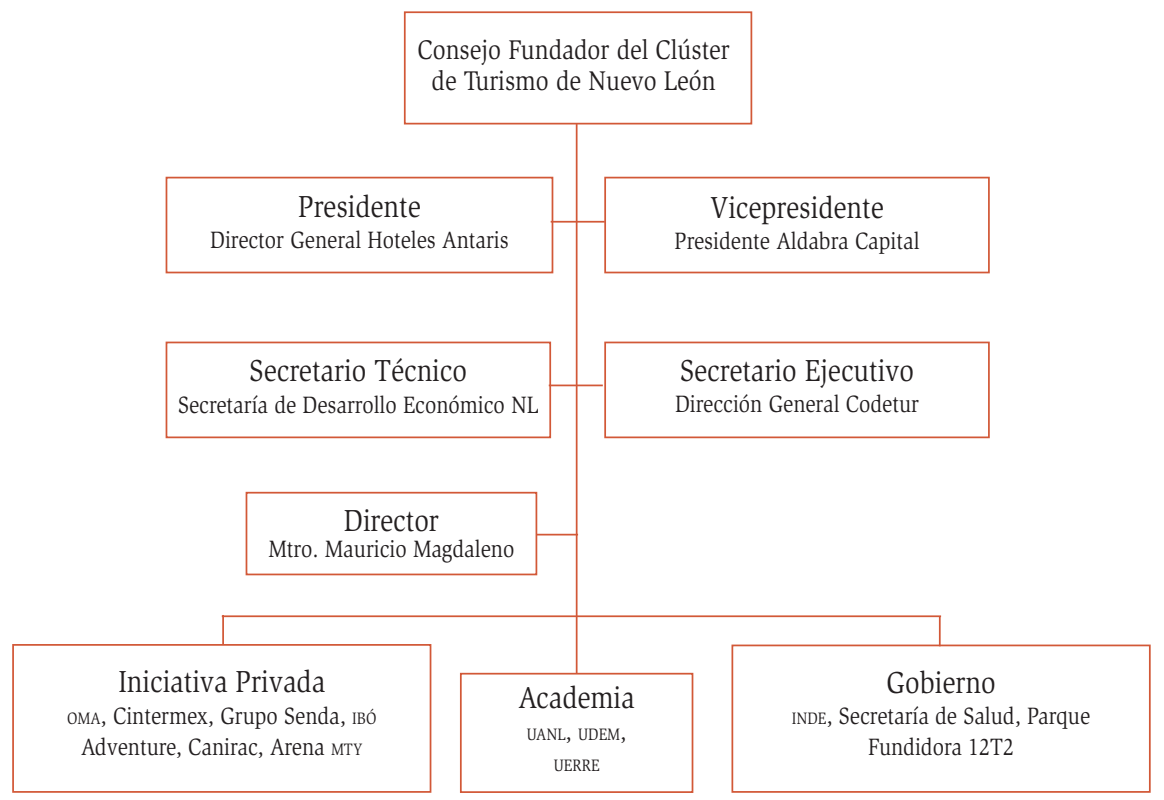

Fuente: Elaboración propia como resultado de la metodología aplicada.

Figura 2. Consejo del Clúster de Turismo de Nuevo León 
El clúster se creó con el propósito de generar y canalizar iniciativas innovadoras lideradas por las empresas de turismo, en colaboración con el sector público y las universidades, además de poner en marcha proyectos y servicios de apoyo a las empresas asociadas y del sector turístico que busquen la competitividad del estado. Dispone de un director ejecutivo con cuatro comités operativos en donde se afilian los consejeros del clúster para ejecutar su planeación estratégica: 1) Comité de Desarrollo de Productos Turísticos Innovadores; 2) Comité de Atención, Atracción y Desarrollo de Magnos Eventos; 3) Comité de Calidad y Desarrollo Humano, y 4) Comité de Gestión del Conocimiento.

De tal suerte, el Clúster de Turismo de Nuevo León se presenta como una propuesta innovadora para la gestión turística en México. No se encuentran documentados otros modelos que, desde la trinchera gubernamental, pretendan regular el sector turístico en nuestro país ni tengan el objetivo de fortalecer entornos competitivos para el desarrollo de la actividad turística y el desarrollo económico de los destinos.

\section{Acciones emprendidas por el Clúster de Turismo de Nuevo León}

Es importante señalar que el funcionamiento del clúster se atribuye primordialmente a la voluntad y la cohesión existente entre los miembros de la cadena de valor del sector turístico de la entidad. Empero, la asociación cuenta con pocos años y se hacen evidentes los desafíos que tiene que sortear para garantizar su posición en la escena nacional y estatal:

- Un mayor trabajo colaborativo entre los sectores público y privado

- Definir con mayor precisión los roles de las instituciones en el destino

- Fomentar el uso de la tecnología para elevar la competitividad turística estatal

- Profesionalizar al capital humano de la industria turística y a los servidores públicos

- Incentivar la movilidad y acceso para las personas discapacitadas

- Crear un Plan Maestro de turismo, incluyendo industria y municipios

- Maximizar la opinión pública sobre el turismo y sus múltiples beneficios

- Atender otros segmentos de mercados y focalizar la prioridad en el cliente

- Se proyecta un amplio trabajo de sensibilización y educación a los 
empresarios del sector turístico, a la sociedad y al gobierno en general, en tanto que el modelo es nuevo en la entidad y en la república mexicana.

En la actualidad, el clúster trabaja mediante el Plan Estratégico del Clúster de Turismo de Nuevo León que es elaborado anualmente y se nutre de los diagnósticos turísticos de la entidad. Se apoya en el Informe Anual de Actividades y Proyectos como instrumento adoptado por el ente para divulgar información y rendir cuentas.

En cuanto a los proyectos y actividades impulsados por el clúster, se fomentan acciones que responden a los objetivos del Plan Estratégico. Entre ellas, la impartición de un Taller de Diagnóstico y Planificación Turística "Destination Next” en el que participaron más de 85 miembros de la industria turística y cuyo resultado fue una evaluación del destino. La herramienta proporcionó información para esbozar estrategias que servirán de insumo en la generación del Programa Sectorial de Turismo de Nuevo León 2017.

Cabe recalcar que el Taller de Diagnóstico y Planificación Turística también expone retos que el clúster debe asumir para lograr cambios significativos en la industria turística, entre ellos, el involucramiento de la comunidad, antes que la experiencia en el destino para los visitantes y que la marca se comprometan; mantener y mejorar la infraestructura turística y los niveles de servicio, y aumentar el perfil y apreciación por la industria del turismo.

Ante este escenario, el clúster cuenta con diferentes estrategias. Algunas ya se encuentran en desarrollo, como la Plataforma Digital de Inteligencia de Mercados Turísticos que promueve el diseño de una app turística del destino no solo para maximizar la experiencia del turista, sino también para recolectar información del mercado y analizar perfiles, tendencias y comportamiento de la demanda. Además el Parque Fundidora albergó el espectáculo "Luminasia”, logrando captar a más de 700000 personas durante todo el mes. Esta exhibición urbana de grandes figuras de luz hechas de tela y metal con temática navideña continúa posicionándose como el evento con mayor cantidad de asistentes en la historia del parque.

Uno más de los proyectos impulsados por el Clúster de Turismo es el fortalecimiento del Festival Internacional de Santa Lucía al realizar una alianza permanente de trabajo colaborativo con el patronato del festival. Por una parte, se gestionó el patrocinio de una startup regiomontana que desarrolla apps móviles 
“Eventto”. Esta empresa contribuyó a difundir el evento y tuvo más de 7000 descargas. Por otra, el Aeropuerto de Monterrey colocó y repartió promocionales del espectáculo. Grupo Senda transmitió el spot promocional en más de 490 unidades y la Asociación de Hoteles de Nuevo León distribuyó el material promocional.

Existen iniciativas para este año como el fomento de productos turísticos, entre ellos el Paseo Mágico, que pretender impactar positivamente a municipios, empresas y prestadores de servicios turísticos de la región citrícola del estado de Nuevo León; el mejoramiento del Turisticbus a través del rediseño de rutas, señalética y paradas; la prestación de asistencia técnica para la gestión de productos o proyectos turísticos, y la publicación de necesidades de investigación en materia turística en la entidad para estudiantes e investigadores.

Desde su creación hasta el momento, el Clúster de Turismo de Nuevo León ha participado en distintas actividades como la Sinergia Interclústers, diplomados en Innovación, y ha sido invitado a participar en paneles para comentar los avances del organismo.

En los últimos dos años, el consenso entre la diversidad de agentes funge como uno de los obstáculos más difíciles de sortear. La recaudación de ingresos y el financiamiento suponen unos de los más grandes desafíos para la prevalencia del clúster.

Así, la experiencia del sector turístico de Nuevo León demuestra que los modelos de gestión para el turismo se constituyen como una poderosa alternativa para que los agentes gubernamentales logren fomentar el desarrollo del sector e impulsen una visión de trabajo colaborativa entre el sector público y el privado.

\section{Conclusiones}

Como se ha plasmado a lo largo de este estudio, el diseño y uso de modelos que parten de la gestión pública surge como una alternativa para que los gobiernos de diferentes niveles impulsen y fomenten la industria turística. Al menos en Nuevo León, el gobierno fue capaz de vincular y organizar a los agentes que intervienen en la actividad turística mediante el Clúster de Turismo, una asociación público-privada que promueve la comunicación y el trabajo coordinado y participativo entre sus miembros. 
El Clúster de Turismo de Nuevo León retomó particularidades de otros modelos de gestión turística en el mundo, así como las opiniones de los agentes inmersos en la cadena de valor del turismo. Tales características se plasman a continuación:

- La convergencia de diferentes sectores en la actividad turística y su importancia para elevar la competitividad del sector turístico.

- La vinculación, cooperación y comunicación entre los sectores público y privado.

- La provisión de servicios turísticos a través de tecnologías de la información, principalmente mediante el diseño de apps.

- La conducción de un turismo que beneficiara a todas las regiones de la entidad y a la población neoleonense.

- La envergadura de contar con planes para el turismo con el objetivo de regular tal actividad.

- Integrar un enfoque de sustentabilidad para el turismo.

- Impulsar la innovación para atraer un mayor número de turistas y hacer destinos competitivos.

Hoy día, es posible observar cambios sustanciales en la gestión y articulación del destino mexicano. Con el nacimiento del clúster, el turismo en Nuevo León ha conferido procesos de gestión innovadores que inciden en la competitividad del destino. La presencia de la sociedad civil, la solidaridad de las empresas, la participación de las instituciones educativas y la intervención de los gobiernos han resultado de vital importancia para la construcción de ideas, propuestas y acciones que en conjunto sobresalen en los proyectos que emanan del clúster.

De igual forma, la organización ha comenzado con una gestión orientada al marketing turístico de calidad, cuyo objetivo reside en identificar, por medio de aplicaciones tecnológicas, el perfil de los turistas que arribarán al destino. Con estos insumos se podrán construir estadísticas turísticas que faciliten el análisis del destino y fortalezcan el planteamiento de propuestas innovadoras para el crecimiento y desarrollo económico de Nuevo León. Por otra parte, el gobierno está adquiriendo habilidad para conducir al turismo bajo principios como el consenso, la corresponsabilidad y el trabajo colaborativo entre los agentes inmersos en el sector. 
Una de las características más trascendentales para este estudio es el grado de profesionalización en la Dirección del Clúster de Turismo de Nuevo León. Sus miembros ostentan grados de licenciatura y maestría en disciplinas relacionadas con el turismo. Derivado de ello, se incrementó el desempeño y calidad en las tareas para promover un modelo de gestión que impulsara la actividad turística. En diferente línea, el modelo turístico neoleonés ha apostado por incorporar aspectos como la comunicación, la participación y la transferencia de conocimientos turísticos que son elementos competitivos para el estado.

Sobre la base de los planteamientos anteriores, se espera que el modelo de gestión turística para Nuevo León sirva de ejemplo para que otras entidades mexicanas puedan reproducir tales esquemas. Para el resto de los destinos, se recomienda diseñar modelos de gestión turística que permanezcan abiertos y se adapten a los cambios que se presentan en la arena turística regional e internacional, con la finalidad de incorporar nuevas visiones que contribuyan a mejorar su funcionamiento. Es imprescindible que los agentes turísticos incluidos en los modelos de gestión ayuden a identificar las condiciones económicas, políticas, sociales y ambientales de los destinos turísticos, a propósito de sugerir estrategias que se acoplen a la realidad de las regiones turísticas. También se sugiere la participación de las universidades y centros de investigación para crear aplicaciones informáticas que permitan difundir los atractivos y productos turísticos de los destinos, así como los sitios de hospedaje, alimentos, bebidas y transporte; el propósito inicial de este tipo de tecnología para el turismo consistirá en captar una parte significativa del mercado turístico regional y, en una segunda fase, del mercado nacional.

Ciertamente, corresponde a los gestores del turismo idear modelos que compaginen con las particularidades de cada uno de los destinos turísticos para obtener modelos diferenciados cuyo enfoque derive siempre en la competitividad del sector. Se abren líneas de investigación para profundizar en la colaboración de la academia a fin de promover la aplicación de tecnologías de la información en el sector turístico mexicano, asimismo, analizar aspectos sobre la profesionalización en el turismo dentro de la administración pública. 


\section{Fuentes consultadas}

Aguilar, L. (2010). Gobernanza: El nuevo proceso de gobernar. México: Fundación Friedrich Naumann para la Libertad.

Barzelay, M. (2003). Introduction: The process dynamic of public management policy making. International Public Management Journal, 6(3), 251281.

Cabrero, E. (1998). Estudio introductorio. En B. Bozeman, La gestión pública. Su situación actual (pp. 19-36). México: Fondo de Cultura Económica. Cravacuore, D. (2006). La articulación de actores para el desarrollo local. Sistema Educativo de Argentina. Recuperado de http://bit.ly/2fPjvct [2016, 16 de abril].

Datatur. (2016). Compendio de estadísticas del turismo de México. México: Secretaría de Turismo.

Federación Española de Municipios y Provincias. (2008). Modelos de gestión turística local. Principios y prácticas. Barcelona: Autor.

Gobierno de la República. (2013). Plan Nacional de Desarrollo 2013-2018. México: Autor.

Isunza, G. y Méndez, B. (2011). Desarrollo inmobiliario y gobiernos locales en la periferia de la Ciudad de México. Eure, 37(111), 107-129.

Madrid, F. F. y Cerón, M. H. (2013). Evaluación de desempeño de los destinos turísticos en el marco de los Convenios de Coordinación en materia de Reasignación de Recursos (CCRR). Análisis del desempeño turístico local y modelo de satisfacción de los turistas. México: Cestur.

Medeiros, L. (2008). Midiendo la competitividad en los destinos: el modelo brasileño. Conferencia en El conocimiento como valor diferencial de los destinos turísticos (pp. 1-26), Málaga. Recuperado de http://statistics. unwto.org/sites/all/files/pdf/barbosa_sp.pdf [2016, 4 de febrero].

Miočić, B. K., Razović, M. y Klarin, T. (2016). Management of sustainable tourism destination through stakeholder cooperation. Management: Journal Of Contemporary Management Issues, 21(2), 99-120.

Morgulis-Yakushev, S. y Sölvell, Ö. (2017). Enhancing dynamism in clusters: A model for evaluating cluster organizations' bridge-building activities 
across cluster gaps. Competitiveness Review, 27(2), 98-112.

Page, S. (2014). Tourism Management. Nueva York: Routledge.

Pulido, J. I. y López, Y. (2013). La innovación como factor de competitividad turística. En J. I. Pulido y P. J. Cárdenas (coords.), Estructura económica de los mercados turísticos (pp. 251-269). Madrid: Síntesis.

Pulido, M. y Pulido, J. I. (2013). Destinos turísticos. Conformación y modelos de gobernanza. En J. I. Pulido y P. J. Cárdenas (coords.), Estructura económica de los mercados turísticos (pp. 179-203). Madrid: Síntesis.

Queiroz, F. y Rastrollo-Horrillo, M. (2015). El estado del arte en gobernanza de destinos turísticos. Tourism \& Management Studies, 11(2), 47-55.

Ramírez, L. (2004). Hacia un análisis crítico de la gestión: Presentando los “Critical Management Studies”. Estado, Gobierno y Gestión Pública. Revista Chilena de Administración Pública, 2(4), 7-25.

Rodríguez, D. y Valldeoriola, J. (2007). Metodología de la investigación. Barcelona: Universitat Oberta de Catalunya.

Sánchez, M. (2013). Competitividad de los destinos turísticos. En J. I. Pulido y P. J. Cárdenas (coords.), Estructura económica de los mercados turísticos (pp. 205-227). Madrid: Síntesis.

Santander, P. (2011). Por qué y cómo hacer análisis de discurso. Cinta de Moebio, 41, 207-244.

Steiner, G. (2003). Planeación estratégica. Lo que todo director debe saber. México: CECSA.

Tarassiouk, A. (2008). Estado y desarrollo. Discurso del Banco Mundial y una visión alternativa. En G. Vidal y A. Guillén, Repensar en la teoría del desarrollo en un contexto de globalización. Homenaje a Celso Furtado (pp. 45-63). México: Universidad Autónoma Metropolitana/Consejo Latinoamericano de Ciencias Sociales.

Valls, J. (2004). Gestión de destinos turísticos sostenibles. Barcelona: Ediciones Gestión 2000.

Varela, M. y Hamui, A. (2013). La técnica de grupos focales. Investigación en Educación Médica, 2(1), 55-60.

Velasco, M. (2014). Gobernanza turística: ¿Políticas públicas innovadoras o retórica banal? Cuaderno Virtual de Turismo, 14(1), 9-22. 
Alternativas de gestión pública para el sector turístico. El caso de Nuevo León, México

Velasco, M. (2010). Gobernanza del turismo: retos y estrategias de las redes de destinos turísticos. Conferencia en Dinámicas de transformación del Turismo en el siglo XXI. Recuperado de http://bit.ly/2fJUmj8 [2016, 4 de febrero].

Yin, R. (2012). Applications of Case Study Research. Thousand Oaks: Sage Publications.

Ying, X., Arcodia, C. y Ruhanen, L. (2013). Innovation and collaboration: The role of the National Government in Norway. Tourism Analysis, 18, 519-531. 